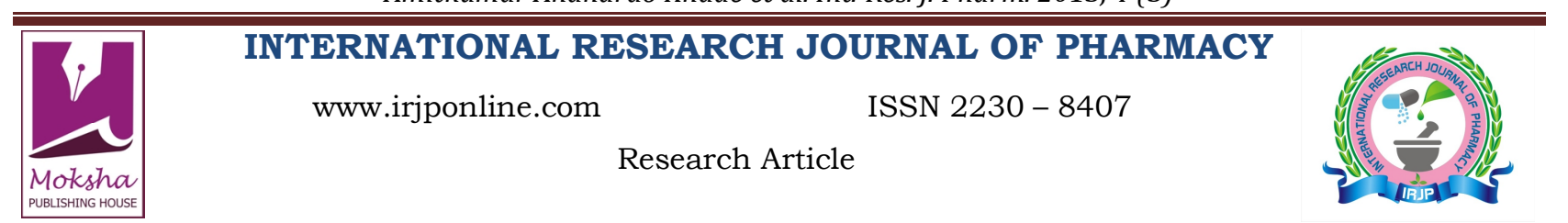

\title{
PATIENT COMPLIANCE IN DOTS BY HIV NON REACTIVE URBAN, SUBURBAN AND RURAL TUBERCULOSIS PATIENTS IN KARAD REGION
}

Amitkumar Anandrao Khade*, Amit kumar, S. V. Kakade

BioAxis DNA Research Centre Private Limited, Sri Lakshmi Nagar Colony, GSI (Post), Bandalaguda, LB Nagar Hyderabad, Andhra Pradesh, India

Email: amit.khade@dnares.in

Article Received on: 09/01/13 Revised on: 01/02/13 Approved for publication: 12/03/13

DOI: $10.7897 / 2230-8407.04336$

IRJP is an official publication of Moksha Publishing House. Website: www.mokshaph.com

(C) All rights reserved.

\section{ABSTRACT}

India accounts for one-fifth of the total global Tuberculosis (TB) incident cases. Each year more than 3,30,000 patients die due to TB. Recently it was found that due to multiple drug therapy, cases of non compliance are increasing. Nowadays TB and Human immunodeficiency virus (HIV) are most common, and are having high prevalence rate. Treatments to both diseases are having various multi-drug therapies; which may interact with each other. The main aim of study was to assess patient compliance rate and comparative assessment in Directly Observed Treatment, Short-course (DOTS) patients with focus on HIV non reactive cases in Karad region, Maharashtra state. The patient compliance was prospectively assessed in 202 individuals from urban, sub-urban and rural hospitals treated for TB. All were HIV non reactive cases. Of the 202 patients, 167 were compliant and 35 were non-compliant. Urban, sub-urban and rural had compliance rates of $79 \%, 92 \%$ and $81 \%$, respectively. Due to various factors like adverse drug reactions, longer duration of the treatment etc. patient compliance to treatment decreases; which acts as one of the high risk factor for Multi-drug-resistant tuberculosis (MDR-TB).

Keywords: Tuberculosis, Compliance, DOTS, Karad, India

\section{INTRODUCTION}

Tuberculosis (TB) causes three million deaths each year that is declared to be 'global health emergency' by World Health Organization (WHO) ${ }^{1}$. TB is also considered as a major public health problem in India. India accounts for one-fifth of the global TB incident cases. Each year nearly 2 million people in India develop $\mathrm{TB}$, of which around 0.87 million are infectious cases. It is estimated that annually around 3, 30,000 Indians die due to $\mathrm{TB}^{2}$.

Hence the Government of India in collaboration with WHO and World Bank launched Revised National Tuberculosis Control Programme (RNTCP) to ensure complete treatment and control of TB as well as to reduce its social burden, but the anti-TB drugs cause higher incidence of Adverse Drug Reactions (ADR) ${ }^{3}$. While long duration of the treatment of TB patients with drugs like Isoniazid, Pyrazinamide, Rifampin, Ethambutol and Streptomycin - the drugs used here are having potential to cause adverse drug reactions like arthralgia, headache, skin rashes etc due to which there is patient noncompliance . $^{4}$

According to a WHO report, $50 \%$ of patients from developed countries with chronic diseases do not use their medications as recommended ${ }^{5}$. Compliance to a medication regimen is generally defined as the extent to which patients take medications as prescribed by their health care providers ${ }^{6}$. Poor compliance has been shown to decrease the effects of prescribed medications or other treatments and to increase the likelihood of poor outcomes ${ }^{7}$. The effectiveness of the treatment for tuberculosis is hampered greatly by the problem of non-compliance. So, we aimed to study the patient compliance rate of DOTS treatment in HIV non reactive patients and compare it in urban, suburban and rural tuberculosis patients in Karad region.

TB with HIV is having high prevalence rate. HIV patients are receiving multiple drug therapies like antiretroviral therapy (ART) as well as they are getting symptomatic treatment. Due to such combinations drug interactions are common. To avoid this confusion we have targeted only DOTS patients with HIV negative cases ${ }^{8}$.

\section{MATERIALS AND METHODOLOGY \\ Location}

The study was conducted on the patients of DOTS with HIV non reactive cases at hospitals providing and monitoring DOTS in Karad region. Karad is largest tehsil in Maharashtra state with population around 1.63 millions.

\section{Period of study}

From $31^{\text {st }}$ March 2010 to $30^{\text {th }}$ September 2012, a prospective evaluation of DOTS patients were undertaken.

\section{Subjects}

A total of 202 newly diagnosed TB patients, who were tested for HIV at Venutai Chavan Hospital Karad (VC). The patients with HIV non reactive reports were participated in study. 90 were attending at Venutai Chavan Hospital, Karad, 63 patients were attending at Primary Health Centre Vadgaon (VH) and 49 were attending at Krishna Hospital, Malkapur (KH) (Figure 1).

\section{Method}

Informed consent was taken from each patient enrolled in this study. After taking the consent of the patient, Case record form was filled. Interviews were conducted by investigator in the national (Hindi) or the local (Marathi) language. The validated questionnaire/forms given to the patients, which elicited information on patient-related factors like sociodemographic, side effects, adverse drug reactions, quality of life and attitude about TB. We obtained data on compliance to treatment schedule from patient treatment cards to evaluate the compliance/non-compliance status.

Patients were kept under observation during their whole treatment period. Patients were instructed to report any signs and symptoms they will come across during the treatment period. 
Amitkumar Anandrao Khade et al. Int. Res. J. Pharm. 2013, 4 (3)

Patients were classified either compliant or non-compliant and compared them on the basis of urban, suburban and rural regions.

Table 1: Compliant-Noncompliant Patients

\begin{tabular}{|c|c|c|c|c|}
\hline & $\begin{array}{c}\text { Urban } \\
\text { (VC) }\end{array}$ & $\begin{array}{c}\text { Suburban } \\
\text { (KH) }\end{array}$ & $\begin{array}{c}\text { Rural } \\
(\mathbf{V H})\end{array}$ & Total \\
\hline $\begin{array}{c}\text { No. of compliant } \\
\text { patient }\end{array}$ & 71 & 45 & 51 & 167 \\
\hline $\begin{array}{c}\text { No. of non- } \\
\text { compliant patient }\end{array}$ & 19 & 4 & 12 & 35 \\
\hline $\begin{array}{c}\text { No. of compliant } \\
\text { male }\end{array}$ & 38 & 27 & 28 & 93 \\
\hline $\begin{array}{c}\text { No. of compliant } \\
\text { female }\end{array}$ & 33 & 18 & 23 & 74 \\
\hline
\end{tabular}

Table 2: Patient compliance rate

\begin{tabular}{|c|c|c|c|c|}
\hline & $\begin{array}{c}\text { Urban } \\
(\mathbf{V C})\end{array}$ & $\begin{array}{c}\text { Suburban } \\
(\mathbf{K H})\end{array}$ & $\begin{array}{c}\text { Rural } \\
(\mathbf{V H})\end{array}$ & Total \\
\hline $\begin{array}{c}\text { Compliance rate } \\
(\%)\end{array}$ & 79 & 92 & 81 & 83 \\
\hline $\begin{array}{c}\text { Non-compliance } \\
\text { rate (\%) }\end{array}$ & 21 & 08 & 19 & 17 \\
\hline $\begin{array}{c}\text { Compliant male } \\
(\%)\end{array}$ & 71.7 & 87 & 80 & 78.1 \\
\hline $\begin{array}{c}\text { Compliant female } \\
(\%)\end{array}$ & 89.1 & 100 & 82.1 & 89.1 \\
\hline
\end{tabular}

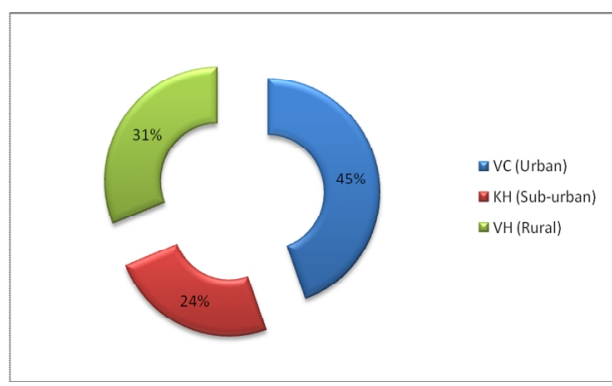

Figure 1. Distribution of patients

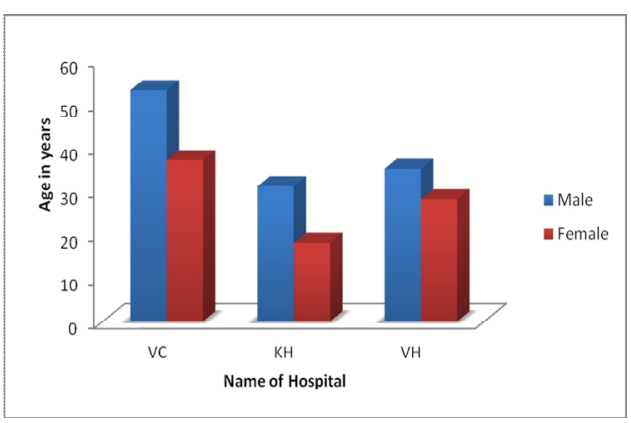

Figure 2. No. of Male-Female

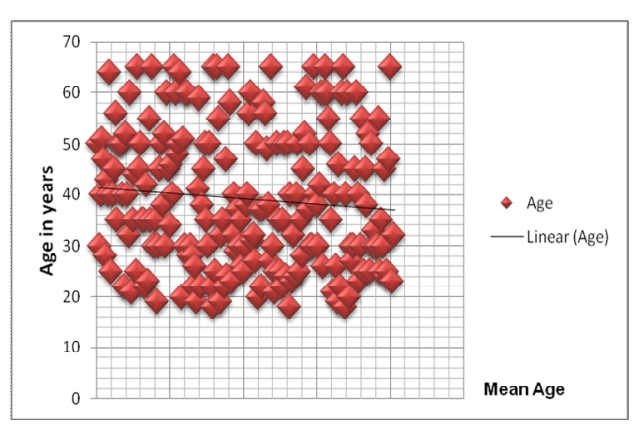

Figure 3. Average Mean age

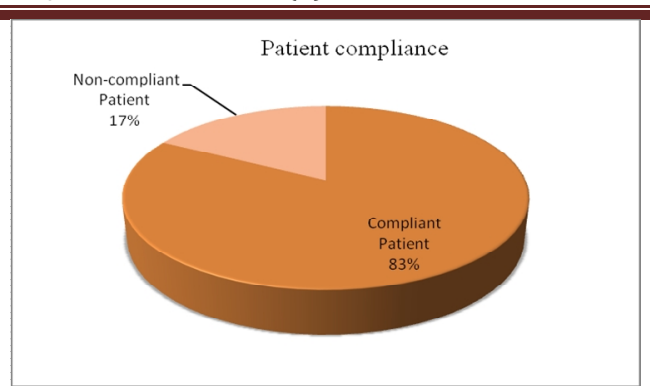

Figure 4. Patient compliance rate

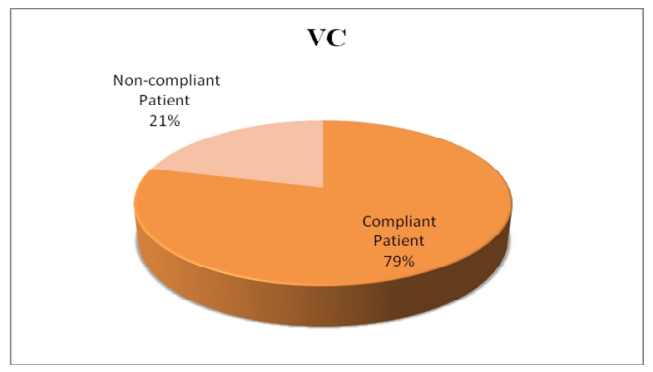

Figure 5. Patient compliance rate - Urban region

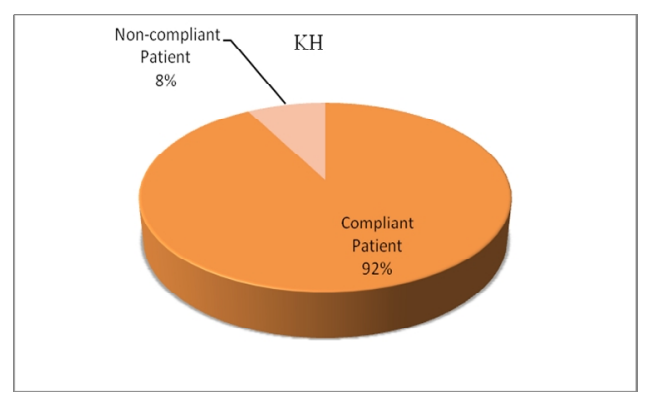

Figure 6. Patient compliance rate - Sub-urban region

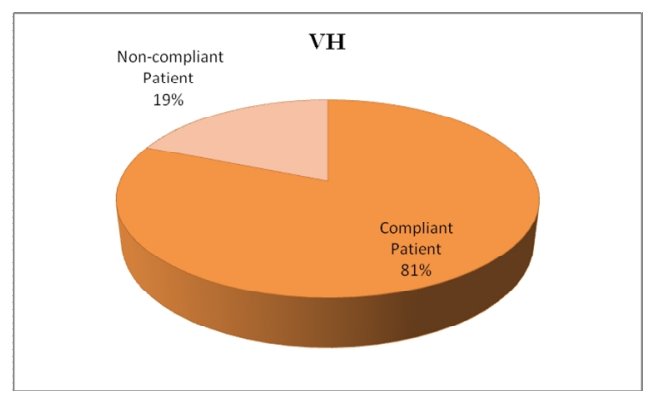

Figure 7. Patient compliance rate - Rural region

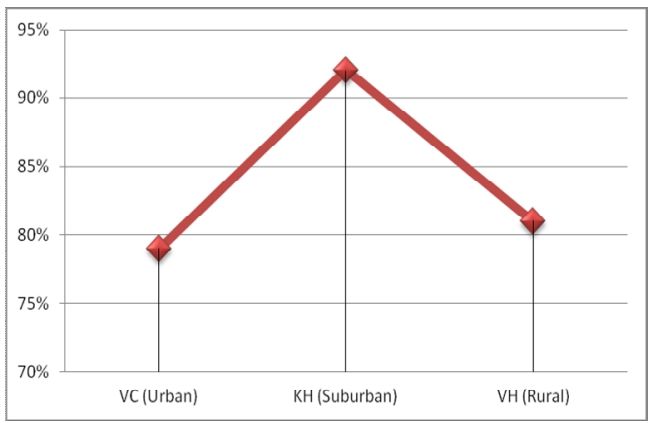

Figure 8. Comparative assessment of compliance rate 


\section{RESULTS}

A total of 202 cases were included in the study carried out from $31^{\text {st }}$ March 2010 to $30^{\text {th }}$ September 2012 for the period of 30 months. Among the studied 202 cases of tuberculosis it was found that mean average age was 39.24 years, 119 males were with mean average age 40.11 years and 83 females with mean average age 38 years (Figure 2 and 3 ).

Out of the 202 patients, $167(83 \%)$ were compliant and 35 (17\%) were non-compliant to medications (Figure 4). Urban, sub-urban and rural has compliance rates of $79 \%(71 / 90)$, $92 \%(45 / 49)$ and 81\% (51/63), respectively (Figure 5,6 and 7). 167 successfully completed and 35 patients did not complete specified treatment period. Among above given 167 patients, 163 cured successfully and 4 failed to cure.

During study it was found that sub-urban patients were more compliant than urban and rural patients. Non- compliance was associated with lack of knowledge about treatment, forgetfulness, socio-economic factors, side effects of drug regimen, poly pharmacy and ADR of the DOTS. There was no statistically significant difference observed in the demographic variables.

\section{DISCUSSION}

\section{Patient compliance in DOTS}

We found that $83 \%$ of patients were compliant to DOTS. Women were more likely to be compliant than men. Among the subgroups of urban, suburban and rural, patient compliance rate were $79 \%, 92 \%$, and $81 \%$ respectively. Previous investigations conducted worldwide among patients receiving DOTS treatment have reported non-compliance rates ranging from 5\% in Malawi to $29.8 \%$ in Zambia ${ }^{9}$.

In our study, sub-urban group had higher compliance rate than urban and rural groups. There was not much significant difference in sex ratio and other environmental, demographic factors. All were from Karad region.

The current study has several strengths such as high participation rate. Patients were selected by random sampling method, thus minimizing selection bias. We used patient treatment cards to define outcome.

Patients with long duration of the treatment and multiple drug therapy are prone to develop non compliance. Multiple or intercurrent disease and multiple drug therapy are responsible for increased risk of discontinuation of the treatment.

Pharmacists may be able to enhance patients compliance and outcomes by engaging in pharmaceutical care activities (eg, monitoring symptoms, providing medication counseling, and helping to resolve drug-related problems, facilitating communication with physicians) ${ }^{10}$.

Poor patient compliance to the treatment regimen is a major cause of treatment failure and of the emergence of drugresistant TB. Previous research reported male sex, poor patient information and communication and $\mathrm{ADR}$ as the major determinants of non-compliance to anti-TB treatment ${ }^{9}$. The prospective study design applied for the current study. Due to small samples in some of the group it was difficult to obtain the equal representative sample in all groups. Finally, findings may not be generalizable to the whole population of the region, which is very diverse in socioeconomic status.
However, they can be generalizable to the population attending the DOTS centers that generally belong to the lower socio-economic status.

\section{CONCLUSION}

We concluded from our study that, the current study evaluated compliance rate and comparative assessment of compliance rate in urban, suburban and rural HIV nonreactive tuberculosis patients receiving DOTS therapy. About one-fifth of the patients were non-compliant. Urban and rural patients are more non-compliant than suburban. Compliance are different among urban-suburban-rural groups.

Due to various determinants like adverse drug reactions, patient compliance to treatment decreases, these determinants are major cause and high risk factor for treatment discontinuation and Multi-drug-resistant tuberculosis (MDRTB). So in future it is necessary to monitor DOTS with special reference to various events like lack of knowledge about treatment, forgetfulness, socio-economic factors, side effects of drug regimen, poly pharmacy and adverse drug reactions of the DOTS occurred during their due course for their success in HIV non reactive tuberculosis cases.

\section{ACKNOWLEDGEMENT}

Authors are thankful to Venutai Chavan Hospital, Karad, PHC Vadgaon, Krishna Hospital, Karad and BioAxis DNA Research Centre (P) Ltd, Hyderabad for supporting at every step and sharing valuable information with us. The kind support from Dr. Nigade is gratefully acknowledged.

\section{REFERENCES}

1. Begum Lutfun Nahar, A.K.M. Mosharrof Hossain. A comparative study on the adverse effects of two anti-tuberculosis drugs regimen in initial two-month treatment period. Bangladesh J Pharmacol 2006; 1: $51-57$

2. whoindia.org. (C) WHO/INDIA: WHO Regional Office for South-East Asia 2010. Updated 2012 July 17. Available from: whoindia.org/en/ Section3/Section123.htm

3. Rao MK, Gupta PP, Chaudhry HN. Study of adverse drug reactions in various regimens under RNTCP - DOTS strategy - preliminary results. Indian J Pharmacol October 2008; Vol 40 Supplement 2: S148

4. K.V. Ramanath, Ramesh.S. A Study on Assessment of Adverse Drug Reactions in Tuberculosis Patients. Am. J. PharmTech Res. 2012; 2(2)

5. Katz Y and Goldberg M. Non-adherence, Non-compliance or Nonconcordance in Asthma: Patients not Following the Medical Regimen. IMAJ 2007;9:389-90.

6. Osterberg L and Blaschke T. Compliance to Medication. N Engl J Med 2005;353:487-97.http://dx.doi.org/10.1056/NEJMra050100 PMid: 16079372

7. Ownby RL. Medical, personal and economic factors influence level of compliance in older adults. Geriatrics 2006 Feb;61( 2):30-5.

8. Amitkumar Anandrao Khade, Amit kumar, Prevalence and Comparative Assessment of Adverse Drug Reactions in Dots with Focus on HIV Negative patients in Karad Region. Helix Vol. 1:243246 (2013).

9. Suparna Bagchi, Guirish Ambe et al. Determinants of Poor Compliance to Anti-Tuberculosis Treatment in Mumbai, India. Int $\mathrm{J}$ Prev Med. 2010 Fall; 1(4): 223-232.

10. Hinchageri S. S. et al. Assessment of medication adherence and factors affecting to medication adherence in asthma patients by clinical pharmacist. IRJP 2012, 3 (3):215

Cite this article as:

Amitkumar Anandrao Khade, Amit kumar, S. V. Kakade. Patient compliance in dots by HIV non reactive urban, suburban and rural tuberculosis patients in Karad region. Int. Res. J. Pharm. 2013; 4(3):174-176 